\section{TRPM8 polymorphisms associated with increased risk of IBS-C and IBS-M}

Recently in Gut, genetic variation affecting ion channels activity has been highlighted in relation to bowel function and the biology of stool frequency. ${ }^{1}$ It is also known that $2 \%$ of patients with IBS carry functional missense mutations in the voltage-gated channel $\mathrm{Na}_{\mathrm{v}} 1.5$ (SCN5A gene). ${ }^{2}$ Hence, channelopathies represent potential abnormalities underlying GI dysfunction and IBS. We inspected data from our previous genome-wide association study (GWAS) of $\mathrm{IBS}^{3}{ }^{3}$ in relation to 27 genes whose ion channel products contribute to GI sensorimotor development and function, visceral sensation and GI motility (see online supplementary table S1). Significant (uncorrected) results were detected for four genes (calcium voltagegated channels CACNA1A and CACNA1E, and transient receptor potential channels TRPV3 and TRPM8; see online supplementary figure S1), which were selected for replication analyses in an independent set of IBS cases $(\mathrm{N}=386)$ and controls $(\mathrm{N}=357)$ (see online supplementary material methods). A sexadjusted logistic regression analysis of genotype data from this cohort (see online supplementary material methods) detected significant associations for TRPM8, and a meta-analysis of GWAS and replication yielded (i) strongest evidence of association at this locus, (ii) no statistical heterogeneity (Cochran's Q test $\mathrm{p}>0.05$ ) and (iii) same direction of genetic risk effects in the two studies (table 1). Rome III IBS-subtype information available for the replication cohort revealed TRPM8 single nucleotide polymorphisms (SNP) to impact IBS risk exclusively in the IBS-C and IBS-M types, with strongest evidence obtained from their

Table 1 Associations between IBS, IBS subtypes and TRPM8 SNPs

\begin{tabular}{|c|c|c|c|c|c|c|c|c|c|c|c|c|c|c|c|}
\hline \multirow[b]{3}{*}{ SNP } & \multirow[b]{3}{*}{$M A(F) \dagger$} & \multicolumn{6}{|c|}{ IBS (GWAS+this study)* } & \multicolumn{8}{|c|}{ IBS subtypes (this study)* } \\
\hline & & \multicolumn{2}{|c|}{$\begin{array}{l}\text { GWAS } \\
\text { (534/4932) }\end{array}$} & \multicolumn{2}{|c|}{$\begin{array}{l}\text { Replication } \\
\text { (386/357) }\end{array}$} & \multicolumn{2}{|c|}{$\begin{array}{l}\text { Meta-analysis } \\
(920 / 5289)\end{array}$} & \multicolumn{2}{|c|}{$\begin{array}{l}\text { IBS-D } \\
(127 / 357)\end{array}$} & \multicolumn{2}{|l|}{$\begin{array}{l}\text { IBS-C } \\
(95 / 357)\end{array}$} & \multicolumn{2}{|c|}{$\begin{array}{l}\text { IBS-M } \\
(163 / 357)\end{array}$} & \multicolumn{2}{|c|}{$\begin{array}{l}\text { IBS-C+M } \\
(258 / 357)\end{array}$} \\
\hline & & $\mathrm{p}$ Value & OR & $p$ Value & OR & $p$ Value & OR & $\mathrm{p}$ Value & OR & $p$ Value & OR & $\mathrm{p}$ Value & OR & $p$ Value & OR \\
\hline rs10519356 & $\mathrm{T}(0.083)$ & $5.1 \mathrm{E}-03$ & 1.35 & $1.3 \mathrm{E}-01$ & 1.36 & $1.5 \mathrm{E}-03$ & 1.35 & $9.0 \mathrm{E}-01$ & 0.96 & $4.4 \mathrm{E}-02$ & 1.79 & $8.5 \mathrm{E}-02$ & 1.52 & $3.4 \mathrm{E}-02$ & 1.59 \\
\hline rs10166942 & $C(0.196)$ & $9.5 \mathrm{E}-03$ & 1.23 & $9.2 \mathrm{E}-04$ & 1.62 & $1.3 \mathrm{E}-04$ & 1.30 & $3.8 \mathrm{E}-01$ & 1.19 & $6.7 \mathrm{E}-03$ & 1.83 & $2.8 \mathrm{E}-04$ & 1.90 & $5.1 \mathrm{E}-05$ & 1.91 \\
\hline rs2362290 & $A(0.196)$ & $9.0 \mathrm{E}-03$ & 1.23 & 7.3E-04 & 1.64 & $1.1 E-04$ & 1.31 & $3.5 \mathrm{E}-01$ & 1.21 & $5.6 \mathrm{E}-03$ & 1.86 & $2.3 \mathrm{E}-04$ & 1.92 & $3.9 \mathrm{E}-05$ & 1.94 \\
\hline rs1003757 & $A(0.087)$ & $4.3 \mathrm{E}-03$ & 1.35 & $1.2 \mathrm{E}-01$ & 1.37 & $1.1 \mathrm{E}-03$ & 1.35 & $8.3 \mathrm{E}-01$ & 0.94 & $5.3 \mathrm{E}-02$ & 1.73 & $6.9 \mathrm{E}-02$ & 1.54 & $2.7 \mathrm{E}-02$ & 1.61 \\
\hline rs1003756 & $\mathrm{T}(0.087)$ & $4.3 \mathrm{E}-03$ & 1.35 & $1.2 \mathrm{E}-01$ & 1.37 & $1.2 \mathrm{E}-03$ & 1.35 & $8.3 \mathrm{E}-01$ & 0.94 & $5.3 \mathrm{E}-02$ & 1.73 & $6.9 \mathrm{E}-02$ & 1.54 & $2.7 \mathrm{E}-02$ & 1.61 \\
\hline rs4497869 & $A(0.107)$ & $1.2 \mathrm{E}-02$ & 1.28 & $3.2 \mathrm{E}-02$ & 1.48 & $1.3 \mathrm{E}-03$ & 1.32 & $6.2 \mathrm{E}-01$ & 1.14 & $3.9 \mathrm{E}-02$ & 1.73 & $3.1 E-02$ & 1.60 & $1.1 \mathrm{E}-02$ & 1.66 \\
\hline rs6431648 & $A(0.208)$ & $5.0 \mathrm{E}-03$ & 1.24 & $4.0 \mathrm{E}-04$ & 1.65 & $3.9 \mathrm{E}-05$ & 1.32 & $2.3 \mathrm{E}-01$ & 1.26 & $8.9 \mathrm{E}-03$ & 1.75 & $2.4 \mathrm{E}-04$ & 1.88 & $3.9 \mathrm{E}-05$ & 1.90 \\
\hline rs758277 & $\mathrm{T}(0.430)$ & $6.1 \mathrm{E}-03$ & 0.83 & $6.7 \mathrm{E}-01$ & 0.95 & $9.6 \mathrm{E}-03$ & 0.86 & $2.8 \mathrm{E}-01$ & 1.18 & $2.7 \mathrm{E}-01$ & 0.82 & $3.9 \mathrm{E}-01$ & 0.88 & $1.9 \mathrm{E}-01$ & 0.84 \\
\hline rs758276 & $\mathrm{G}(0.207)$ & $5.6 \mathrm{E}-03$ & 1.24 & $4.9 \mathrm{E}-04$ & 1.64 & $4.9 \mathrm{E}-05$ & 1.32 & $2.2 \mathrm{E}-01$ & 1.27 & $8.7 \mathrm{E}-03$ & 1.75 & $4.3 \mathrm{E}-04$ & 1.83 & $6.0 \mathrm{E}-05$ & 1.87 \\
\hline rs758275 & $\mathrm{G}(0.206)$ & $5.5 \mathrm{E}-03$ & 1.24 & $5.4 \mathrm{E}-04$ & 1.63 & $5.0 \mathrm{E}-05$ & 1.32 & $2.2 \mathrm{E}-01$ & 1.27 & $1.1 \mathrm{E}-02$ & 1.73 & $4.3 \mathrm{E}-04$ & 1.83 & $7.0 \mathrm{E}-05$ & 1.86 \\
\hline rs6711120 & $A(0.208)$ & $6.0 \mathrm{E}-03$ & 1.24 & $4.9 \mathrm{E}-04$ & 1.64 & $5.2 \mathrm{E}-05$ & 1.32 & $2.2 \mathrm{E}-01$ & 1.27 & $8.7 \mathrm{E}-03$ & 1.75 & 4.3E-04 & 1.83 & $6.0 \mathrm{E}-05$ & 1.87 \\
\hline rs 9646720 & $G(0.204)$ & $5.0 \mathrm{E}-03$ & 1.25 & $1.0 \mathrm{E}-03$ & 1.60 & $5.9 \mathrm{E}-05$ & 1.32 & $2.2 \mathrm{E}-01$ & 1.28 & $2.7 \mathrm{E}-02$ & 1.62 & $5.9 \mathrm{E}-04$ & 1.82 & $1.9 \mathrm{E}-04$ & 1.80 \\
\hline rs7595960 & $A(0.110)$ & $6.5 \mathrm{E}-03$ & 1.29 & $3.5 \mathrm{E}-02$ & 1.48 & $7.5 \mathrm{E}-04$ & 1.33 & $6.0 \mathrm{E}-01$ & 1.14 & $4.7 \mathrm{E}-02$ & 1.70 & 3.5E-02 & 1.60 & $1.3 \mathrm{E}-02$ & 1.64 \\
\hline rs7577157 & $A(0.111)$ & $7.3 \mathrm{E}-03$ & 1.29 & $3.5 \mathrm{E}-02$ & 1.48 & $8.4 \mathrm{E}-04$ & 1.33 & $6.0 \mathrm{E}-01$ & 1.14 & 4.7E-02 & 1.70 & $3.5 \mathrm{E}-02$ & 1.60 & $1.3 \mathrm{E}-02$ & 1.64 \\
\hline
\end{tabular}




\begin{tabular}{lccccc}
\multicolumn{5}{c}{ Correlation between TRPM8 genotype and BSFS scores } \\
\hline SNP & $\begin{array}{c}\text { Test } \\
\text { (minor) } \\
\text { allele }\end{array}$ & $\begin{array}{c}\text { Genetic risk } \\
\text { effect in IBS }\end{array}$ & $\begin{array}{c}\text { Allele } \\
\text { frequency }\end{array}$ & P & Rho \\
\hline rs10519356 & T & predisposing & 0,083 & $\mathbf{2 , 9 E - 0 2}$ & $-0,174$ \\
rs10166942 & C & predisposing & 0,208 & $\mathbf{3 , 3 E - 0 2}$ & $-0,169$ \\
rs1003757 & A & predisposing & 0,095 & $\mathbf{3 , 5 E - 0 2}$ & $-0,166$ \\
rs1003756 & T & predisposing & 0,095 & $\mathbf{3 , 9 E - 0 2}$ & $-0,162$ \\
rs6431648 & A & predisposing & 0,212 & $\mathbf{7 , 7 E - 0 3}$ & $-0,221$ \\
rs758277 & T & protecting & 0,417 & $\mathbf{1 , 5 E - 0 2}$ & 0,199 \\
rs7577157 & A & predisposing & $\mathbf{0 , 1 0 7}$ & $\mathbf{2 , 3 E - 0 2}$ & $-0,184$ \\
\hline
\end{tabular}

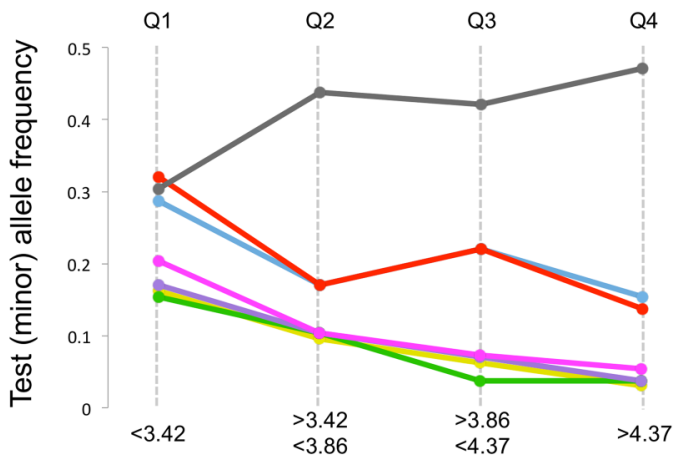

Average BSFS quartiles $(N=30$ each $Q)$

Figure 1 Correlation between TRPM8 genotype and average Bristol Stool Form Scale (BSFS) scores. Left: Spearman correlation statistics. Right: frequency of TRPM8 alleles across BSFS quartile groups (alleles from each SNP are colour-coded as in the table on the left).

combined analysis (table 1). This prompted us to investigate the relationship between TRPM 8 and GI motility in the Populationbased Colonoscopy study (PopCol), ${ }^{4}$ focusing on IBS-free individuals $(\mathrm{N}=120)$ who kept weekly records of their defaecation episodes based on the Bristol Stool Form Scale (BSFS; see online supplementary material methods). A Spearman correlation analysis revealed all IBS-C/M risk alleles to be consistently associated with harder stools, showing progressively decreasing frequencies from lower to upper average BSFS quartile groups, while opposite results were obtained for protective alleles (figure 1).

Dysregulated transient receptor potential (TRP) channel activity has been associated to IBS and constipation, and peppermint oil (which contains the TRPM8 activator menthol as its biologically active ingredient) is reported to induce symptoms relief in patients with IBS and to exert spasmolytic effects and inhibition of GI contractility. ${ }^{5-7}$ TRPM8 SNP associations with slower colonic transit, constipation and IBS may thus result from allele-specific effects on TRPM 8 function (due to coding variants) and/or expression (due to regulatory variants) in the GI tract. In the meta-analysis, strongest association and IBS-C/M risk effects were observed for two SNPs (rs10166942 and rs2362290; table 1) mapping in the promoter region of the gene where transcriptional regulation takes place. These markers are computationally predicted to alter the transcription factor (TF) binding at the corresponding DNA sites and, in addition to expected transcription-related activities, pathway analysis of this TF pool yielded 'abnormal hepatobiliary system' as the top scoring mammalian phenotype (see online supplementary material methods and table S2). Additional pathway analyses of TRPM8 coexpressed genes (see online supplementary material methods), returned 'bile secretion', 'bile acid and bile salt transport' and 'bile acid metabolic process' as the main biological processes (see online supplementary table S3). These are potentially important observations, since the mechanisms regulating TRPM8 expression are poorly characterised, and alterations of bile acid synthesis and metabolism are implicated as causative mechanisms linked to constipation and IBS. ${ }^{8}$

In summary, we identify TRPM 8 polymorphisms that associate with slower colonic transit rates and increased risk of IBS with constipation (IBS-C and IBS-M). These results may contribute to identifying subsets of patients with IBS for improved therapeutic precision, and provide novel opportunities for mechanistic investigation of IBS symptom generation.

\section{Maria Henström, ${ }^{1}$ Fatemeh Hadizadeh, ${ }^{1,2}$ Arthur Beyder, ${ }^{3}$ Ferdinando Bonfiglio, ${ }^{1,4}$ Tenghao Zheng, ${ }^{1}$ Ghazaleh Assadi, ${ }^{1}$ Joseph Rafter, ${ }^{1}$ Luis Bujanda, ${ }^{4}$ Lars Agreus, ${ }^{5}$ Anna Andreasson, ${ }^{5,6}$ Aldona Dlugosz, Greger Lindberg, ${ }^{7}$ Peter T Schmidt, ${ }^{7}$ Pontus Karling, ${ }^{8}$ Bodil Ohlsson, ${ }^{9}$ Nicholas J Talley, ${ }^{10}$ Magnus Simren, ${ }^{11}$ Susanna Walter, ${ }^{12}$ Mira Wouters, ${ }^{13}$ Gianrico Farrugia, ${ }^{3}$ Mauro D'Amato ${ }^{4,14,15,16}$}

${ }^{1}$ Department of Biosciences and Nutrition, Karolinska Institutet, Stockholm, Sweden

${ }^{2}$ School of Nutrition, Isfahan University of Medical Sciences, Isfahan, Iran

${ }^{3}$ Enteric Neuroscience Program, Division of Gastroenterology and Hepatology, Department of Physiology and Biomedical Engineering, Mayo Clinic, Rochester, Minnesota, USA

${ }^{4}$ Department of Gastrointestinal and Liver Diseases, BioDonostia Health Research Institute, San Sebastian, Spain

${ }^{5}$ Division for Family Medicine, Department of Neurobiology, Care Sciences and Society, Karolinska Institutet, Stockholm, Sweden

${ }^{6}$ Stress Research Institute, Stockholm University,

Stockholm, Sweden

${ }^{7}$ Department of Medicine, Karolinska Institutet, Center for Digestive Diseases, Karolinska University Hospital Huddinge, Stockholm, Sweden

${ }^{8}$ Division of Medicine, Department of Public Health and Clinical Medicine, Umeå University, Umeå, Sweden
${ }^{9}$ Department of Internal Medicine, Lund University, Skåne University Hospital, Sweden

${ }^{10}$ Faculty of Health and Medicine, University of Newcastle, Newcastle, New South Wales, Australia

${ }^{11}$ Department of Internal Medicine and Clinical Nutrition, Institute of Medicine, Sahlgrenska Academy, University of Gothenburg, Gothenburg, Sweden

${ }^{12}$ Division of Neuro and Inflammation Science, Department of Clinical and Experimental Medicine, Linköping University, Linköping, Sweden

${ }^{13}$ Translational Research Center for Gastrointestinal Disorders (TARGID), Leuven University, Leuven, Belgium

${ }^{14}$ BioCruces Health Research Institute, Bilbao, Spain

${ }^{15}$ IKERBASQUE, Basque Foundation for Science, Bilbao, Spain

${ }^{16}$ Clinical Epidemiology Unit, Department of Medicine Solna, Karolinska Institutet, Stockholm, Sweden

Correspondence to Professor Mauro D'Amato, BioDonostia Health Research Institute, Donostia University Hospital, Paseo Dr Begiristain $s / n$, San Sebastian E-200014, Spain; mauro.damato@ biodonostia.org

Contributors $\mathrm{MH}, \mathrm{AB}, \mathrm{GF}$ and $\mathrm{MD}$ : study concept and design; TZ, JR, LB, LA, AA, AD, GL, PTS, PK, BO, NJT, MS and SW: characterisation of study individuals, acquisition of data; GA: genotyping; $\mathrm{MH}$, $\mathrm{FH}, \mathrm{FB}$ and $\mathrm{MD}$ : statistical analyses; $\mathrm{MH}, \mathrm{AB}, \mathrm{MW}$, GF and MD: analysis and interpretation of data; $M H$, $A B$, GF and $M D$ : drafting of the manuscript, with critical revision for important intellectual content by all other authors.

Funding This work was supported by grants from The Swedish Research Council (VR 2013-3862) and the Department of Health of the Basque Government (2015111133) to MD. MD and GF are the recipients of a KI-Mayo Collaborative Research Grant for the study of genetic channelopathies in IBS.

Competing interests None.

Ethics approval Karolinska Institutet Ethics Review Board

Provenance and peer review Not commissioned; internally peer reviewed.

- Additional material is published online only. To view please visit the journal online (http://dx.doi.org/10. 1136/gutjnl-2016-313346).

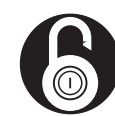
OPEN ACCESS 
Open Access This is an Open Access article distributed in accordance with the Creative Commons Attribution Non Commercial (CC BY-NC 4.0) license, which permits others to distribute, remix, adapt, build upon this work non-commercially, and license their derivative works on different terms, provided the original work is properly cited and the use is non-commercial. See: http:/l creativecommons.org/licenses/by-nc/4.0/

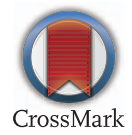

To cite Henström M, Hadizadeh F, Beyder A, et al Gut 2017;66:1725-1727.

Received 3 November 2016

Revised 20 November 2016

Accepted 23 November 2016

Published Online First 14 December 2017

Gut 2017;66:1725-1727.

doi:10.1136/gutjnl-2016-313346

\section{REFERENCES}

1 Jankipersadsing $\mathrm{SA}$, Hadizadeh F, Bonder MJ, et al. A GWAS meta-analysis suggests roles for xenobiotic metabolism and ion channel activity in the biology of stool frequency. Gut Epub ahead of print: $29 \mathrm{Jul}$ 2016. doi: 10.1136/gutjnl-2016-312398

2 Beyder A, Mazzone A, Strege PR, et al. Loss-offunction of the voltage-gated sodium channel $\mathrm{NaV1.5}$ (channelopathies) in patients with irritable bowel syndrome. Gastroenterology 2014;146: 1659-68.

3 Ek WE, Reznichenko A, Ripke $S$, et al. Exploring the genetics of irritable bowel syndrome: a GWA study in the general population and replication in multinational case-control cohorts. Gut 2015;64:1774-82.

4 Walter SA, Kjellström L, Nyhlin $\mathrm{H}$, et al. Assessment of normal bowel habits in the general adult population: the Popcol study. Scand I Gastroenterol 2010;45:

556-66.
5 Blackshaw LA. Transient receptor potential cation channels in visceral sensory pathways. $\mathrm{Br}$ I Pharmacol 2014;171:2528-36.

6 Khanna R, MacDonald JK, Levesque BG. Peppermint oil for the treatment of irritable bowel syndrome: a systematic review and meta-analysis. J Clin Gastroenterol 2014;48:505-12.

7 Amato A, Liotta R, Mulè F. Effects of menthol on circular smooth muscle of human colon: analysis of the mechanism of action. Eur I Pharmacol 2014;740:295-301.

8 Camilleri M, Gores GJ. Therapeutic targeting of bile acids. Am I Physiol Gastrointest Liver Physiol 2015;309:G209-15. 